\title{
Penerapan Model Technology Acceptance Model (TAM) untuk Pemahaman Media Pembelajaran Berbasis Multimedia Interaktif
}

\author{
Agusdi Syafrizal $^{1}$, Ernawati ${ }^{2}$, B.Yudi Dwiandiyanta ${ }^{3}$ \\ ${ }^{12,3}$ Program Studi Magister Teknik Informatika, Universitas Atma Jaya Yogyakarta \\ Email: ${ }^{1}$ agusdi1308@gmail.com, ${ }^{2}$ ernawati@mail.uajy.ac.id, ${ }^{3}$ yudi_dwi@mail.uajy.ac.id
}

\begin{abstract}
Abstrak
Penerapan model Technology Acceptance Model (TAM) bertujuan untuk mengukur tingkat pemahaman terhadap media pembelajaran yang berbentuk multimedia interaktif. Pada umumnya, dosen hanya mengandalkan metode ceramah dan tanya jawab di dalam proses pembelajaran. Dalam artikel ini dosen yang mengajar meminta untuk menginovasi sistem pembelajaran, yaitu dengan menggunakan multimedia interaktif. Peneliti menggunakan jenis data kuantitatif, dengan metode analisis yang digunakan adalah deskriptif, sedangkan metode pengumpulan data diperoleh dari kuesioner dan observasi. Untuk memahami penerimaan dan penggunaan media pembelajaran berbasis multimedia interaktif bisa diukur dengan menggunakan model penerimaan teknologi (TAM). Model TAM dapat menjelaskan bahwa persepsi pengguna akan menentukan sikapnya dalam penerimaan penggunaan Teknologi Informasi (TI). Model ini secara lebih jelas menggambarkan bahwa penerima penggunaan TI dipengaruhi oleh kemanfaatan (usefulness).
\end{abstract}

Kata Kunci: Technology Acceptance Model (TAM), Media pembelajaran, Multimedia interaktif

\section{PENDAHULUAN}

Pendidikan sebagai salah satu bagian tidak terpisahkan dari proses pendewasaan manusia tentu di satu sisi memiliki peranan yang besar bagi pengembangan ilmu pengetahuan dan teknologi tersebut. Namun, di sisi lain pendidikan juga perlu memanfaatkan kemajuan ilmu pengetahuan dan teknologi agar mampu mencapai tujuan secara efektif dan efisien [1]. Kualitas pendidikan dapat dipengaruhi oleh kurikulum, proses pembelajaran, metode pengajaran, evaluasi, buku ajar, mutu guru, saran dan prasarana pendidikan [2]. Dalam dunia pendidikan, pemanfaatan perangkat Teknologi Informasi dan Komunikasi (TIK) sangat membantu proses belajar mengajar [3]. Seperti yang disebutkan dalam laporan hasil penelitian yang dikeluarkan oleh Computer Technology Research bahwa seseorang hanya akan mendapat $20 \%$ dari apa yang mereka lihat dan 30\% dari yang mereka dengar. Sedangkan melalui multimedia akan mendapat $50 \%$ dari apa yang mereka lihat dan dengar sampai $80 \%$ dari apa yang mereka lihat, dengar dan berinteraksi dengan pada waktu yang sama [4].

Komputer sebagai salah satu produk TIK dinilai tepat digunakan sebagai alat bantu dalam pembelajaran, berbagai macam pendekatan pembelajaran yang dikemas dalam bentuk program pembelajaran berbentuk komputer atau Computer Assisted Instruction (CAI) [5]. Dengan berkembangnya TIK dalam pembelajaran ini, sehingga dengan metode ekspositori dirasakan belum memadai. Dengan demikian media pembelajaran 
berbasis multimedia yang tepat untuk meningkatkan hasil belajar yang efisien dan dapat meningkatkan efektifitas belajar.

Media pembelajaran berbasis multimedia interaktif sudah banyak diproduksi secara luas, tetapi media pembelajaran yang diproduksi tanpa memahami kurikulum pelajaran dan kebutuhan user. Oleh karena itu diperlukan pengembangan multimedia pembelajaran yang diharapkan dapat disajikan sebagai penunjang dalam mengatasi kesulitan dalam materi pelajaran.

TAM merupakan model penerimaan teknologi yang paling berpengaruh dan paling banyak digunakan pada studi di bidang Technology Information [6]. Studi TAM terdahulu secara luas telah menggunakan berbagai jenis model dengan maksud untuk mendapatkan cara pandang yang lebih luas serta penjelasan yang lebih baik mengenai proses penerimaan teknologi pada individu [7]. Pada penelitian terdahulu, terbukti bahwa TAM dapat digunakan untuk mengukur tingkat penerimaan e-learning di SMK Labor Pekanbaru dengan sangat baik [8].

Akan dikembangkan model pembelajaran dengan pembuatan aplikasi multimedia interaktif untuk dapat dijadikan sebagai penunjang dan pendukung dalam pembelajaran, pengembangan bentuk aplikasi media pembelajaran yang mudah dan interaktif bagi user, membuat model penerimaan media pembelajaran bagi user dan mengetahui pengaruh tingkat penerimaan media pembelajaran pada materi pelajaran.

\section{METODE}

Model pengembangan ini bertujuan untuk mengembangkan media pembelajaran berbasis multimedia interaktif yang dapat digunakan dalam proses belajar dan untuk meningkatkan motivasi belajar bagi pengguna. Model pengembangan yang digunakan adalah metode penelitian dan pengembangan atau dikenal dengan istilah Research And Development (R\&D). Metode penelitian dan pengembangan adalah metode penelitian yang digunakan untuk menghasilkan produk tertentu dan menguji keefektifan produk tersebut [9]. Pertama-tama dibuat media pembelajaran berbasis multimedia interaktif. Selanjutnya, dibuat kuesioner untuk dengan metode TAM untuk mengukur tingkat penerimaan pengguna terhadap media pembelajaran.

Metode yang digunakan adalah penelitian kuantitatif. Sedangkan metode analisis data yang digunakan adalah metode statistik deskriptif. Dalam hal ini peneliti menggunakan data primer yang diperoleh dengan cara menyebarkan kuesioner dan data sekunder yaitu berupa data dari user yang menggunakan media pembelajaran ini.

Cakupan pada metodologi terdiri dari cara dan model penelitian yang digunakan. Adapun metodologi disini dapat mencakup teori-teori yang digunakan pada tinjauan pustaka yang didapatkan pada literatur. 


\section{PEMBAHASAN}

Dalam pembahasan ini, secara garis besar alur yang digunakan dapat ditunjukkan dengan Gambar 1.

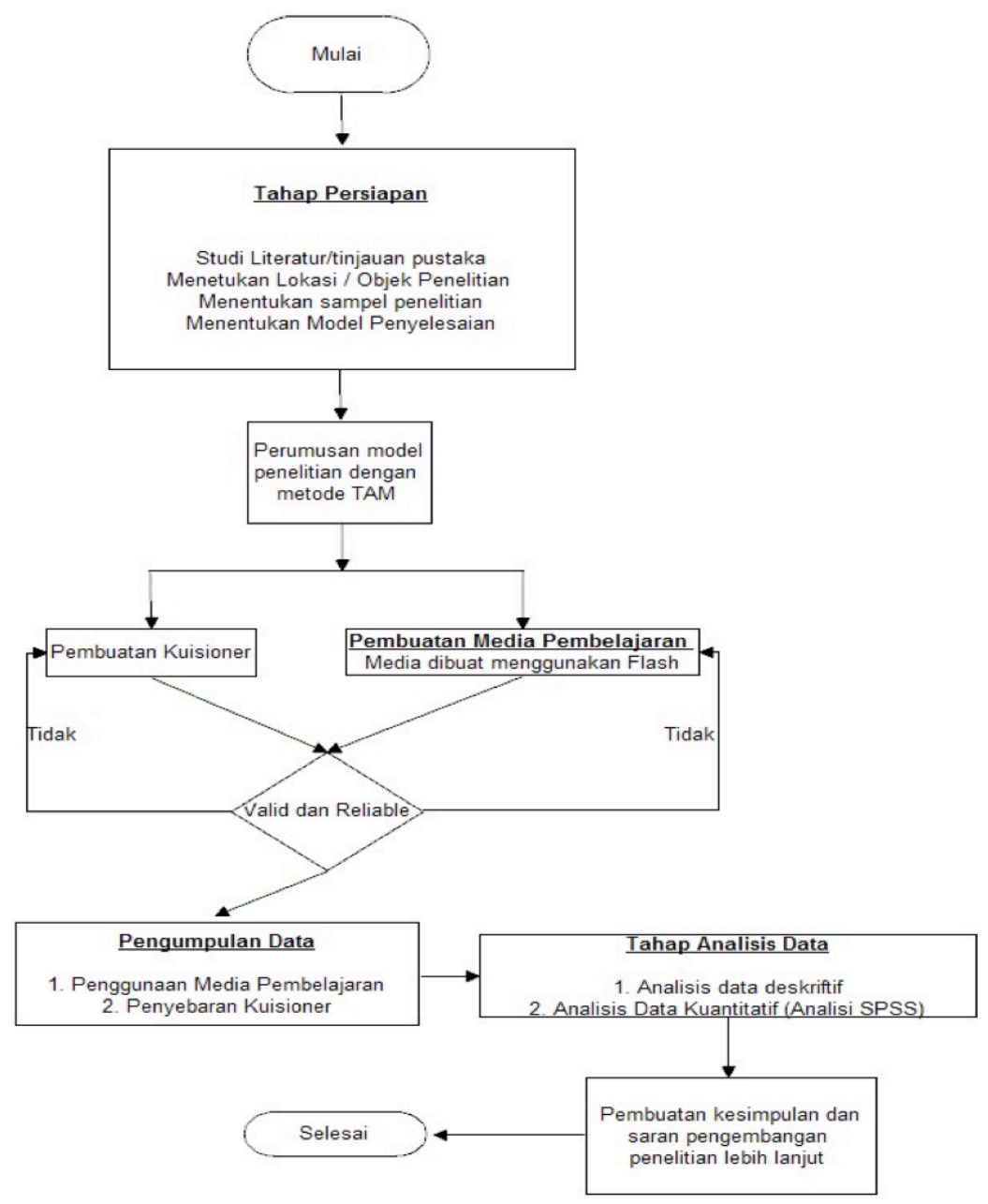

Gambar 1. Alur penelitian

Dalam [10] diungkapkan mengenai lima tahap pengembangan multimedia yaitu tahapan analisis, desain, pengembangan, implementasi dan penilaian yang melihat aspek pengguna, lingkungan pembelajaran, kurikulum, prototipe, penggunaan dan penyempurnaan sistem. Visualisasi dari kelima tahap tersebut terdapat pada Gambar 2. 


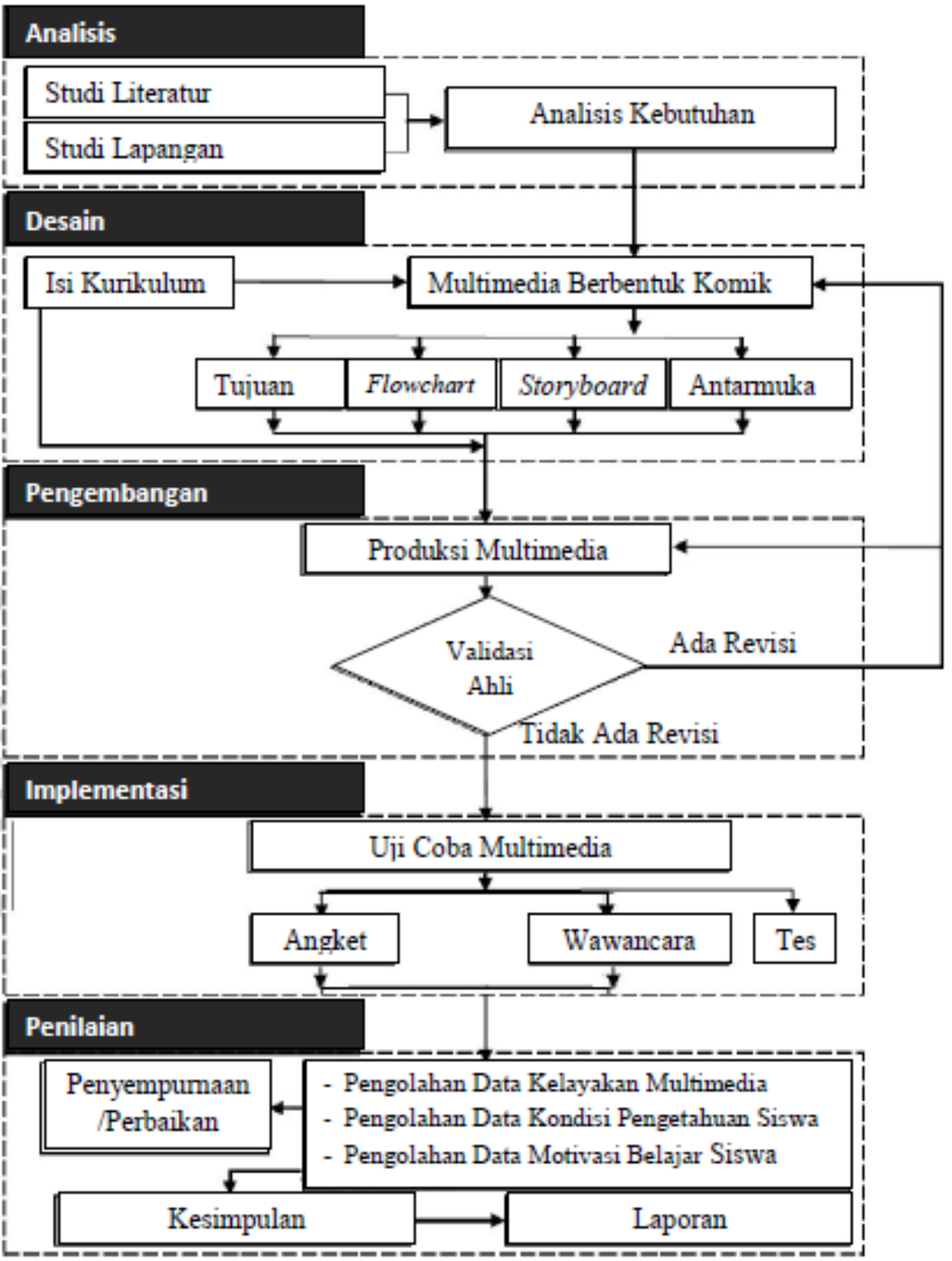

Gambar 2. Model pengembangan media pembelajaran

Model pengembangan multimedia yang diungkapkan Munir merupakan modifikasi menyesuaikan dan mengadaptasi baik dari model pengembangan sebelumnya untuk menghasilkan produk yaitu multimedia pembelajaran. Oleh kerena itu, model pengembangan tersebut dimodifikasi disesuaikan dan diadaptasi dalam penelitian sehingga menghasilkan model pengembangan yang tetap mengacu pada model 
pengembangan tersebut di atas dan tetap bertujuan untuk mengembangkan multimedia pembelajaran sehingga prosedur penelitian dan pengembangan yang akan digunakan.

Metode pengumpulan data adalah menggunakan data yang diperoleh dari kuesioner yang diisi responden. Selain dengan kuesioner, pengumpulan data juga dilakukan dengan observasi yang bertujuannya adalah mendapatkan data tentang pengaruh faktorfaktor yang mempengaruhi kesuksesan media pembelajaran ini.

Metode analisis yang digunakan adalah deskriptif merupakan dasar bagi semua penelitian. Penelitian deskriptif dapat dilakukan secara kuantitatif agar dapat dilakukan analisis statistik, sedangkan teknik pengolahan data menggunakan penghitungan komputasi program SPSS (Statistical Product and Service Solution) karena program ini memiliki kemampuan analisis statistic cukup tinggi serta sistem manajemen data pada lingkungan grafik menggunakan menu-menu dekriptif.

Akan diukur penggunaan sistem berdasarkan Keinginan Pengunaan (Behavioral Intention) melalui 3 kontruksi utama yaitu Perilaku Penggunaan (Attitude), Kegunaan yang Disarankan (Perceived Use), dan Kemudahan Pengunaan yang Disarankan (Perceived Ease of Use).

\section{SIMPULAN}

Pembuatan media pembelajaran berbasis multimedia interaktif sedang dalam proses. Hasil dari pembuatan media pembelajaran ini untuk mengetahui hasil penerapan model Technology Acceptance Model (TAM) dalam memahami penerimaan media pembelajaran ini dan sebagai ide dalam penerapan TAM pada media pembelajaran berbasis multimedia interaktif dan sebagai pedoman bagi penelitian selanjutnya.

\section{REFERENSI}

[1] Muhson, A. 2009. Staf Pengajar Jurusan Pendidikan Akuntansi. s.1: Universitas Negeri Yogyakarta.

[2] Fitria, Aida, N., dan Nurhayati. 2014. Pengembangan Media Pembelajaran Modulasi Sinyal Analog dan Digital Berbasis Multimedia Flash untuk Menunjang Perkuliahan Dasar Sistem Telekomunikasi Mahasiswa S1 Teknik Elektro. Jurnal Pendidikan Elektro. Vol. 3(3): 579-585.

[3] Mohammadi, N., Ghorbani, V., dan Hamidi, F. 2011. Effects of E-Learning on Language Learning. Procedia Computer Science. Vol. 3(1): 464-468.

[4] Suyanto, M. 2005. Multimedia: Alat untuk Meningkatkan Keunggulan Bersaing. Yogyakarta: Percetakan Andi.

[5] Yazid. 2008. Media Pembelajaran Kimia Berbantuan Komputer (MPKBK). Yogyakarta, Universitas Negeri Yogyakarta.

[6] Lee, Chan, B., Yoon, J.O., and Lee, I. 2009. Learners' Acceptance of E-Learning in South Korea: Theories and Results. Computers and Education. Vol. 53(4): $1320-1329$.

[7] Legris, P, Ingham J., dan Collerette, P. 2003. Why Do People Use Information Technology? A Critical Review of the Technology Acceptance Model. Information \& Management. Vol. 40(3): 191-204. 
[8] Dalimunthe, N., Wibisono, H. 2013. Analisis Penerimaan Sistem E-Learning SMK Labor Pekanbaru dengan Menggunakan Techology Acceptance Model (TAM). Jurnal Sains, Teknologi, dan Industri UIN SUSKA Riau. Vol. 11(2): 111117.

[9] Sugiyono. 2009. Metode Penelitian Kuantitatid dan R\&D. Jakarta, Alfabeta.

[10] Munir. 2008. Kurikulum Berbasis Teknologi Informasi dan Komunikasi . Bandung, SPS Universitas Pendidikan Indonesia. 